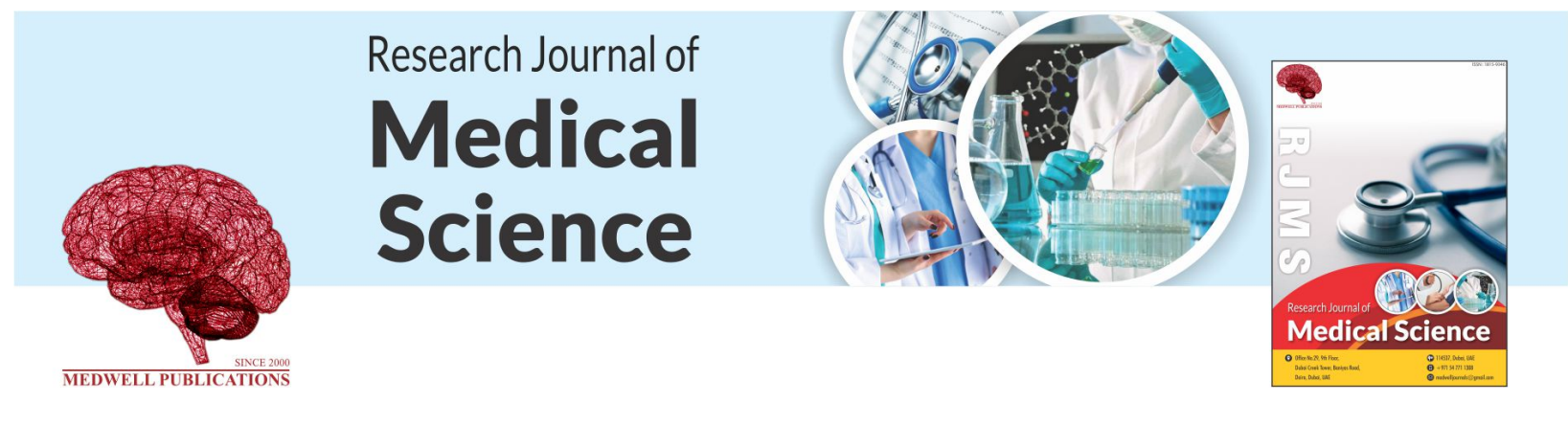

\title{
Academic Satisfaction Among Nursing College Students in Basra
}

Samira Mohammed Ebrahim

Department of Community Medicine, Nursing College, University of Basra, Iraq

Key words: Satisfaction, students, teaching, resources, support, significant

\section{Corresponding Author:}

Samira Mohammed Ebrahim

Department of Community Medicine, Nursing College, University of Basra, Iraq

Page No.: 15-19

Volume: 14, Issue 1, 2020

ISSN: $1815-9346$

Research Journal of Medical Sciences

Copy Right: Medwell Publications
Abstract: This study was conducted to estimate the rate of satisfaction among undergraduate Basra Nursing College Students. The research population consists of all the students of nursing studying at the second to 4 th year of nursing college (103 students). Data collection instrument was a research questionnaire. The questionnaire used contain 2 parts the first part consist of items related to demographic features and the other part contain questions related to nursing student's satisfaction level about 3 major topics (Satisfaction with clinical teaching, Satisfaction with in-class teaching and satisfaction with support and resources). About $64.1 \%$ of the students were satisfied with clinical teaching (79.6\%) with in-class teaching and $(77.7 \%)$ were satisfied with support and resources and the overall satisfaction was (74.8\%). Regarding socio demographic characteristics $80 \%$ of males and $73.5 \%$ of females were satisfied, $80.6 \%$ of second academic year students were satisfied, higher than those in third and fourth year $(72.7 \%, 71.8 \%)$, respectively. Majority of student were satisfied with in-class teaching with support and resources. The least satisfaction among the students was for clinical training. Males were more satisfied than females and as academic years increase, nursing student's satisfaction gradually decreases, although, differences were not significant.

\section{INTRODUCTION}

Student's satisfaction is a short-term attitude resulting from an evaluation of their educational experience, services and facilities ${ }^{[1]}$. Quality of lecturers, physical facilities and effective use of technology can be considered as main factors for satisfaction of students. Recently in universities student's opinions are considered as necessary factors to evaluate quality ${ }^{[2,3]}$.

The level of student's satisfaction to choose learning course is a key factor that should be considered in academic education system improvement ${ }^{[4]}$. Therefore, knowledge on how satisfaction develops, changes and how it affects academic engagement will be useful to everyone who is involved in shaping and improving the academic learning environment ${ }^{[5]}$.

In a cross-sectional research performed in one of Nursing and Midwifery Schools in Ahvaz, to evaluate the nursing student's satisfaction about their field of study. The results of the study revealed that most students had little satisfaction concerning their field of study ${ }^{[3]}$. 
In study conducted at the University of Agricultural Sciences and Veterinary Medicine of Cluj-Napoca, Romania. The aim was to emphasize the "positive factors" that contribute to improving the educational process and increasing student satisfaction with the teaching activity. Most of the students appreciate as good teacher personality traits: openness to dialogue, human nature and his personal experience in the area of study and his explanatory skills in delivering scientific information $^{[6]}$.

A study was conducted at Technical Nursing Institute in Cairo University to investigate the relationship between nursing student's clinical placement satisfaction, academic self-efficacy and achievement. The researchers found that $70.8 \%$ of the students were satisfied with their clinical placement ${ }^{[7]}$.

The result of study done on sample of 463 undergraduate nursing students from the 3 universities in Cyprus Republic showed that nursing students were highly satisfied with the clinical learning environment and their satisfaction has been positively related to all clinical learning environment constructs ${ }^{[8]}$.

Concerning the degree of satisfaction with the academic experience, the result of a study including 170 undergraduate nursing students from a public university in southern Brazil showed that students were neither dissatisfied nor satisfied with the institution, the course and the opportunity of development ${ }^{[9]}$.

Aiming to assess nursing student's level of satisfaction with their clinical learning environments, a study was conducted at the Faculty of Nursing, Menoufia University, Egypt including 400 Nursing students. The results showed that students have a medium level of satisfaction with their clinical learning environments ${ }^{[10]}$.

In a cross sectional study conducted in eight Universities in Kenya. The study concluded that there is a significant and direct relationship between quality of teaching facilities, availability of textbooks in the library and quality of library service environment and studen't satisfaction in the universities. An improvement in the level of provision of these dimensions was likely to result to a proportionate increase in student's satisfaction in the universities $^{[11]}$.

In Italy a cross-sectional study was conducted in a sample of 173 nursing students the main finding was that the student's experiences of and satisfaction with the supervisory relationship and the role of nurse teacher depend on how supervision in the clinical practice and in the simulation laboratory is organized ${ }^{[12]}$.

Descriptive study conducted at King Saud University including 147 undergraduate bachelor student's revealed moderate level satisfaction in clinical placement ${ }^{[13]}$.
Aim of the study: The aim of this study is to estimate the academic satisfaction among Basra Nursing College students.

\section{MATERIALS AND METHODS}

Design of the study: Descriptive cross-sectional study.

Setting of the study: Nursing College of Basra.

Sample of the study: Total of 103 students in the second, 3rd and 4th year. For the purpose of the data collection modified questionnaire from previous studies was used ${ }^{[14]}$ data collection was carried out from October, 2018 through November, 2018. The questionnaire contain 2 parts the first part related to demographic features and the other part contain questions related to nursing student's satisfaction level about 3 major topics (Satisfaction with clinical training, satisfaction with in-class teaching and satisfaction with support and resources). The questionnaire ordered on a five-point Likert scale from strongly unsatisfied to strongly satisfied (1-5 points). Students satisfaction was classified later into 2 categories (satisfied) and (not satisfied). The data was collected by 3 seiner nursing students by face-to-face interviews. Each interview session took 7-10 min.

Data analysis, the Statistical Package for the Social Sciences (SPSS) Version 23.0 was used. Data was expressed in (frequency and percentage). Chi-squared was used to examine the association between the groups and probability of $<0.05$ was considered to statistically significant.

\section{RESULTS AND DISCUSSION}

Table 1 showed that the majority of the sample were females $(80.6 \%)$, sample mean age 21.33 years and $37.9 \%$ of the sample were in the fourth year. Majority (90.3\%) of the students were satisfied with item (Clinical instructors are open to discussions and difference of opinions). Only (35.9\%) were satisfied with (clinical instructors make sure that you are prepared before you care you're your assigned patients) as shown in Table 2.

\begin{tabular}{llcc}
\multicolumn{4}{l}{ Table 1: Socio demographic characteristics of participants $(\mathrm{n}=103)$} \\
$\begin{array}{l}\text { Characteristics of } \\
\text { participants }\end{array}$ & Categories & Frequency & Percentage \\
\hline Gender & Male & 20 & 19.4 \\
& Female & 83 & 80.6 \\
Age in years & & & \\
Mean 21.33 \pm 2.7 & $18-20$ & 41 & 39.8 \\
& $21+$ & 62 & 60.2 \\
Academic years & Second & 31 & 30.1 \\
& Third & 33 & 32 \\
& Fourth & 39 & 37.9 \\
\hline
\end{tabular}


Table 3 showed that $(91.3 \%)$ of students were satisfied with item related to (Faculty members make every effort to assist students when asked) while only (61.2\%) of the students were satisfied with response to the item (Faculty members try to make their subject item (Faculty members try to make their subject interesting).

Table 4 showed that majority of students $(91.3 \%)$ were satisfied with availability of support at the clinical and computer labs. Only $35.9 \%$ were satisfied with availability of channels for expressing student complaints. Table 5 showed that majority (79.6\%) of students were satisfied with in-class teaching followed by $77.7 \%$ were satisfied with support and resources and only (64.1\%) were satisfaction with clinical training and the rate of students who were satisfied with all aspects of teaching methods was $74.8 \%$.

Regarding socio demographic characteristics, $(80 \%)$ of males were satisfied more than females and $80.6 \%$ of students in second academic year were satisfied, higher than those in other academic years although the differences were statistically not significant as shown in Table 6.

Student's satisfaction is a good factor to verify their acceptance of the educational environment and conditions and show their believes about discipline and teaching facilities ${ }^{[4]}$. Regarding gender females constitute the

Table 2: Satisfaction of students with clinical training $(n=103)$

\begin{tabular}{|c|c|c|c|c|}
\hline \multirow[b]{2}{*}{ Items related to clinical instructors } & \multicolumn{2}{|c|}{ Not satisfied } & \multicolumn{2}{|c|}{ Satisfied } \\
\hline & No. & Percentage & No. & Percentage \\
\hline They give you clear ideas of what is expected of you in a clinical rotation & 22 & 21.4 & 81 & 78.6 \\
\hline They Provide enough opportunities for independent practice in the lab or clinical sites & 31 & 30.1 & 72 & 69.9 \\
\hline They are available when needed & 13 & 12.6 & 90 & 87.4 \\
\hline They assign you to patients that are appropriate to your level of competence & 58 & 56.3 & 45 & 43.7 \\
\hline They encourage you to link theory to practice & 31 & 30.1 & 72 & 69.9 \\
\hline They make sure that you are prepared before you care you're your assigned patients & 66 & 64.1 & 37 & 35.9 \\
\hline They give you sufficient guidance before you perform technical skills & 16 & 15.5 & 87 & 84.5 \\
\hline They give you verbal and written feedback concerning your clinical experience & 59 & 57.3 & 44 & 42.7 \\
\hline They view your mistakes as part of your learning & 22 & 21.4 & 81 & 78.6 \\
\hline They demonstrate a high level knowledge and clinical expertise & 16 & 15.5 & 87 & 84.5 \\
\hline They provide feedback at appropriate times, and do not embarrass you in front of others & 53 & 51.5 & 50 & 48.5 \\
\hline They are open to discussions and difference of opinions & 10 & 9.7 & 93 & 90.3 \\
\hline They are well thought and provide excellent learning experiences & 47 & 45.6 & 56 & 54.4 \\
\hline
\end{tabular}

Table 3: Satisfaction of students with in-class teaching $(\mathrm{n}=103)$

\begin{tabular}{|c|c|c|c|c|}
\hline \multirow[b]{2}{*}{ Items related to faculty members } & \multicolumn{2}{|c|}{ Not satisfied } & \multicolumn{2}{|c|}{ Satisfied } \\
\hline & No. & Percentage & No. & Percentage \\
\hline The quality of instruction you receive in your classes is good and helpful & 16 & 15.5 & 87 & 84.5 \\
\hline They are fair and unbiased in their treatment of individual students & 31 & 30.1 & 72 & 69.9 \\
\hline They demonstrate a high level of knowledge in their subject area & 12 & 11.7 & 91 & 88.3 \\
\hline They make appropriate use of modern technology and audio-visual aids to enhance my learning & 17 & 16.5 & 86 & 83.5 \\
\hline They provide adequate feedback about student progress in a course & 11 & 10.7 & 92 & 89.3 \\
\hline They are usually available after class and during office hours & 10 & 9.7 & 93 & 90.3 \\
\hline They make every effort to assist students when asked & 9 & 8.7 & 94 & 91.3 \\
\hline They are very good at explaining things & 19 & 18.4 & 84 & 81.6 \\
\hline They make an effort to understand difficulties you might be having with my coursework & 36 & 35 & 67 & 65 \\
\hline They try to make their subject interesting & 40 & 38.8 & 63 & 61.2 \\
\hline
\end{tabular}

Table 4: Satisfaction of students with support and resources $(n=103)$

\begin{tabular}{|c|c|c|c|c|}
\hline \multirow[b]{2}{*}{ Items related to support and resources } & \multicolumn{2}{|c|}{ Not satisfied } & \multicolumn{2}{|c|}{ Satisfied } \\
\hline & No. & Percentage & No. & Percentage \\
\hline Adequacy of Library resources and services for learning needs & 17 & 16.5 & 86 & 83.5 \\
\hline Availability of Required textbooks and other learning materials & 18 & 17.5 & 85 & 82.5 \\
\hline $\begin{array}{l}\text { Computer and clinical labs are well equipped, adequately staffed and } \\
\text { are readily accessible to meet your learning needs }\end{array}$ & 25 & 24.3 & 78 & 75.7 \\
\hline Availability of Support at the clinical and computer labs & 9 & 8.7 & 94 & 91.3 \\
\hline Availability of Channels for expressing student complaints & 66 & 64.1 & 37 & 35.9 \\
\hline The secretaries are caring and helpful & 11 & 10.7 & 92 & 89.3 \\
\hline The administration shows concern for students as individuals & 42 & 40.8 & 61 & 59.2 \\
\hline
\end{tabular}


Res. J. Med. Sci., 14 (1): 15-19, 2020

Table 5: Satisfaction of students with teaching methods $(n=103)$

\begin{tabular}{llccc}
\hline & Not satisfied & & Satisfied \\
Teaching methods & - & Percentage & No. & Percentage \\
\hline Satisfaction of participants with clinical training & No. & 37.9 & 66 & 64.1 \\
Satisfaction of participants with in-class teaching & 21 & 20.4 & 82 & 79.6 \\
Satisfaction of participants with support and resources & 23 & 22.3 & 80 & 77.7 \\
Overall satisfaction & 26 & 25.2 & 77 & 74.8 \\
\hline
\end{tabular}

Table 6: Satisfaction of students with teaching methods related to socio demographic characteristics of $(n=103)$

\begin{tabular}{|c|c|c|c|c|c|c|c|}
\hline \multirow[b]{2}{*}{ Characteristics } & \multicolumn{2}{|c|}{ Not satisfied } & \multicolumn{2}{|c|}{ Satisfied } & \multirow[b]{2}{*}{$\mathrm{X} 2$} & \multirow[b]{2}{*}{ Df } & \multirow[b]{2}{*}{ p-values } \\
\hline & No. & Percentage & No. & Percentage & & & \\
\hline \multicolumn{8}{|l|}{ Gender } \\
\hline Males & 4 & 20 & 16 & 80 & 0.362 & 1 & 0.548 \\
\hline Females & 22 & 26.5 & 61 & 73.5 & & & \\
\hline \multicolumn{8}{|l|}{ Academic years } \\
\hline Second & 6 & 19.4 & 25 & 80.6 & 0.823 & 2 & 0.663 \\
\hline Third & 9 & 27.3 & 24 & 72.7 & & & \\
\hline Fourth & 11 & 28.2 & 28 & 71.8 & & & \\
\hline Total & 26 & 25.2 & 77 & 74.8 & & & \\
\hline
\end{tabular}

majority of students, this agrees with country policy to encourage the recruitment of females in the field of nursing.

In the present study, most students $74.8 \%$ were satisfied with their teaching methods in their field of study, lower than other study done in Palestine where $80.7 \%$ nursing students were satisfied ${ }^{[15]}$ and higher than that for the Yemen $58.6 \%{ }^{[16]}$. While satisfaction of students with clinical training reported by $64.1 \%$ this rate was higher than study done in $\operatorname{Iran}^{[10,17]}$. And lower than the result in study done in Egypt ${ }^{[7]}$.

Satisfaction with in-class teaching was reported by $79.6 \%$ of the students, higher than study done in $\operatorname{Iran}^{[3,10]}$ and lower than study done in Egypt $82.4 \%{ }^{[9]}$. Regarding satisfaction with the (Faculty members making appropriate use of modern technology $83.5 \%$ of students were satisfied, higher than study done in Romania $42.64 \%{ }^{[6]}$. Satisfaction with the Faculty member's demonstration of a high level of knowledge in their subject area was reported by $88.3 \%$ of the students, higher than study done in Romania $85.29 \%{ }^{[6]}$.

Regarding support and resources $77.7 \%$ of the students were satisfied the rate was higher than other studies in Kenya and in Western Europe ${ }^{[11,18]}$. Also 75.7\% were satisfied with the item (Computer and clinical labs are well equipped, adequately staffed and are readily accessible to meet your learning needs) the rate was higher than study done in Kenya ${ }^{[1]]}$. Regarding the satisfaction with the availability of the required textbooks and other learning materials $82.5 \%$ was higher than study done in Kenya $34 \%{ }^{[11]}$.

Although, male students showed satisfaction more than female students, however, no significant difference in satisfaction rate appeared between males and females, similar to the findings in other studies ${ }^{[9,14,19]}$. In this study as academic years increase, nursing student's satisfaction gradually decreases similar findings in other studies ${ }^{[4]}$ this could be explained by that more awareness gained about the field difficulties and their maturity about their professional life in future ${ }^{[20]}$.

\section{CONCLUSION}

Majority of student were satisfied with in-class teaching, followed with support and resources and the least satisfaction among the students was for clinical training. Males were more satisfied than females and students in second academic year were satisfied, higher than those in other academic years, although, the differences were statistically not significant.

\section{RECOMMENDATIONS}

Collaboration between the nursing college and health care institution is important to ensure student's satisfaction with their clinical learning environments. And nursing instructors should try to improve the quality of their educational provision and increase the satisfaction of their students.

\section{REFERENCES}

01. Weerasinghe, I.S., R. Lalitha and S. Fernando, 2017. Student's satisfaction in higher education literature review. Am. J. Educ. Res., 5: 533-539.

02. Wilkins, S. and M.S. Balakrishnan, 2013. Assessing student satisfaction in transnational higher education. Int. J. Educ. Manage., 27: 143-156. 
03. Hakim, A., 2014. Nursing student's satisfaction about their field of study. J. Adv. Med. Educ. Professionalism, 2: 82-87.

04. Shakurnia, A., H. Alijani, N. Khajeali and S.R. NiakanKalhori, 2015. Nursing students motivations and satisfaction, do the motivation and satisfaction of nursing students change during their study years?. J. Health Med. Nurs., 13: 28-34.

05. iskan, B.O.O. and B.A. Mercangoz, 2013. Satisfaction and academic engagement among undergraduate students. Int. J. Res. Bus. Social Sci., 2: 84-92.

06. Roman, I., 2014. Qualitative methods for determining students satisfaction with teaching quality. Procedia Social Behav. Sci., 149: 825-830.

07. Al Sebaee, H.A., E.M.A. Aziz and N.T. Mohamed, 2017. Relationship between nursing student's clinical placement satisfaction, academic self-efficacy and achievement. IOSR. J. Nurs. Health Sci., 6: 101-112.

08. Papastavrou, E., M. Dimitriadou, H. Tsangari and C. Andreou, 2016. Nursing student's satisfaction of the clinical learning environment: A research study. BMC. Nurs., Vol. 15, 10.1186/s12912-016-0164-4

09. Ramos, A.M., J.G.T. Barlem, V.L. Lunardi, E.L.D. Barlem, R.S.D. Silveira and S.S. Bordignon, 2015. Satisfaction with academic experience among undergraduate nursing students. Texto Contexto-Enfermagem, 24: 87-195.

10. Mokadem, N.M.E., E.L. Shimaa and S. Ibraheem, 2017. Nursing students satisfaction with their clinical learning environments. Am. J. Nurs., 5: 104-108.

11. Kara, A.M., E.K. Tanui and J.M. Kalai, 2016. Quality of academic resources and students satisfaction in public universities in Kenya. Int. J. Learn. Teach. Educ. Res., 15: 130-146.
12. Cremonini, V., P. Ferri, G. Artioli, L. Sarli, E. Piccioni and I. Rubbi, 2015. Nursing student's experiences of and satisfaction with the clinical learning environment: the role of educational models in the simulation laboratory and in clinical practice. Acta Biomed Health Professions, 86: 194-204.

13. Alenazi, L., 2016. Satisfaction nursing students in clinical placement. Int. Educ. Res. J. (IERJ.), 2: 50-51.

14. Dennison, S. and M.M. El-Masri, 2012. Development and psychometric assessment of the undergraduate nursing student academic satisfaction scale (UNSASS). J. Nurs. Meas., 20: 75-89.

15. Salameh, B.S., 2017. Self-confidence and satisfaction among nursing students with the use of high fidelity simulation at Arab American University, Palestine. Int. J. Health Life Sci., 3: $15-23$.

16. Almahbashi, T., S. Aljunid and A. Ismail, 2015. Determinants of health profession student satisfaction with educational services. Malaysian J. Publ. Health Med., 15: 32-39.

17. Nasab H.S., H.H.R. Jahan, R.R. Tavakoli, A.R.A. Delavari and H.H. Rafati, 2010. Amount of health-treatment services management bachelor students' satisfaction from their educational field. J. Educ. Strategy Med. Sci., 3: 5-6.

18. Herdlein, R. and E. Zurner, 2015. Student satisfaction, needs and learning outcomes: A case study approach at a European University. SAGE Open, Vol. 5, 10.1177/2158244015580373.

19. El Ansari, W., 2002. Student nurse satisfaction levels with their courses: Part I-effects of demographic variables. Nurse Educ. Today, 22: 159-170.

20. Abaszadeh, A. and F. Borhani, 2012. Factors affecting discipline (Major) choice among newly admitted students of nursing in Kerman University of medical sciences. Iran. J. Med. Educ., 11: 600-608. 